\title{
Putting Plays (And More) In Cyberspace: An Overview of the British Women Playwrights around 1800 Project
}

\section{Thomas Crochunis \& Michael Eberle-Sinatra}

To cite this article: Thomas Crochunis \& Michael Eberle-Sinatra (2003) Putting Plays (And More) In Cyberspace: An Overview of the British Women Playwrights around 1800 Project, European Romantic Review, 14:1, 117-131, DOI: $10.1080 / 10509580303680$

To link to this article: http://dx.doi.org/10.1080/10509580303680

曲 Published online: 17 Sep 2010.

Submit your article to this journal ¿

Џll Article views: 14

Q View related articles $\sqsubset$

Citing articles: 1 View citing articles 저 


\title{
PUTTING PLAYS (AND MORE) IN CYBERSPACE: AN OVERVIEW OF THE BRITISH WOMEN PLAYWRIGHTS AROUND 1800 PROJECT
}

\author{
Thomas C. Crochunis and Michael Eberle-Sinatra
}

The BRITISH Women Playwrights around 1800 Web project has had a split allegiance from its beginning. ${ }^{1}$ Its beginnings lay in our interest in sustaining over time a community that had begun exploring the histories and writing of women in late-eighteenth and earlynineteenth century British theater. However, the project has also sought to accumulate materials and commentary about these women playwrights so that scholars and students of the humanities, including those outside the emerging community actively investigating women's dramatic writing of this era, would have a centeral in-depth information source. Although we knew from the beginning that the task was not as straightforward as recovering the neglected plays written by women and putting them online, we have discovered little by little that critiquing scholarly practice is essential to opening a space for neglected histories. For example, the constraints placed on inquiry in women's theater history by the business of scholarly publishing have made an electronic project seem a comfortable fit for our work; we see this realization as both a fortuitous circumstance and a relevant excerise that reveals how historiographic practices affect historical knowledge. Interestingly, one of the results of our online project has been increased interest from publishers and editors about the work being done on British women playwrights of the years around $1800 .^{2}$

We draw attention to both our performance and critique of historiography because we believe that our project's self-conscious straddling of these dual loyalties is what makes it potentially important to electronic scholarship. Readers of this essay who have visited the site know that we are not an exhaustive database of plays by women. Nor are we a scholarly journal, a set of hypertext editions, or a site where performance of these plays is being documented. Over time, we might become these things, but for now we remain provisional, shaping the venue through the dialogue between offers of content from 
members of the evolving working group and importunate requests by the general editors seeking to extend in new directions the body of easily accessible information on British women playwrights. We could have set about constructing an exhaustive database of texts or a series of working papers by scholars or a series of downloadable-videotaped performance experiments. It seemed wrong, however, to establish the methods we would use from the start because we began with questions about how scholarly procedures have contributed to the disappearance of these women playwrights and about how electronic tools might make women's theater history newly available in unforeseen ways. In short, we have allowed the parameters of our site to remain undefined, emergent, because the work we are hoping to foster needs to self-consciously question its relationship to established scholarly procedures.

\section{FOUR UNDERLYING IDEAS}

The four main propositions that inform how we think about our historical subject and our methods in developing the site are founded on our belief that the formation of a scholarly venue like ours can produce extremely valuable methodological self-reflection. This selfconsciousness can influence our practical decisions about the site's development and initiate critique of scholarly historiography, and its often unexamined assumptions about how dramatic writing relates to theatrical performance and publishing.

\section{Play Texts Are a Distinctive Kind of Historical Artifact}

The role of play texts in the historical representation of cultural authorship has not yet been addressed by scholarly editing. Part of the problem is the difficulty of defining the very thing at the supposed center of our project: dramatic composition. (We use "dramatic composition" strategically to signal our site's openness to viewing writing as only one possible medium for composing performances.) If part of the impulse in textual editing is toward some form of representation of the historical, play texts complicate that task immensely. First, they raise questions about what ought to be represented-the manuscript artifacts whose relationship with subsequent performances is uncertain, the traces of the performance itself, or the published text that can have any of a number of relationships to staging? While these three choices might have significant textual similarities, they can be quite different in some cases and their purposes as historical representations are certainly distinct. Second, play texts complicate authorial intention beyond all measure, since any such intention must be interpreted in relation to complexes of social process, interpretation, and counter-intention that make the versions of literary texts seem simple by comparison. Finally, play texts are artifacts in a medium-words on paper - that is different from the medium of performance. Although the textual medium determines the artifact's form, the play script was used within a series of social processes (rehearsal, reading, licensing). Therefore, textual artifacts related to theater need to be understood as gestures within social contexts toward artistic intentions. All three of these complications ought to give us pause when we think about how and why to publish a theater text electronically or in print as part of an act of historical representation. The 
uncertain, unstable - and, yes, playful — nature of dramatic compositions thus finds an analogue in the performative aspects of site navigation.

\section{Reading Play Texts Requires New Protocols of Interpretation}

The uses to which play texts might be put by those using electronic resources - that is, how theater materials might be "read" — differ from how literary texts are read because of the range of different purposes that can motivate the textual form of a play script. Even if we simplified our reading by focusing on a playwright's intention, we would need to read a play script in relation to its theatrical context since plays invoke the theater as actual or imaginative venue. But there is more complication: to read women's theater writing of the period around 1800, it is essential to do more than read single plays or an author's oeuvre as literary writing. Not only does reading beyond the literary allow for an awareness of women's plays as a family of texts similarly influenced and sometimes similarly structured, but it also reminds us that reception of these plays in either theaters or print responded to both their literary content and their engagement with social processes such as those of the patent or minor theaters of London. Furthermore, all these nuances of scholarly interpretation aside, these plays might also be read today by theater practitioners seeking possible performance texts ${ }^{3}$ and by students with an interest in women's writing. After all, since these plays have been left out of the educational canon, it is possible that people will have never been taught about them and might just find them surprisingly interesting to think about, read aloud, imagine in performance. This possible interest in non-scholarly reading adds further complication to how we publish the texts since we cannot assume that a dense historiographic apparatus will support all possible kinds of reading.

\section{Studying Women's Writing for Theater Requires Sociological Methods}

The social contexts bearing on women's theater writing in the years around 1800-as cultural production then and as object of scholarship now-differentiate it from other forms of cultural production of its time, like poetry or the novel. While there are many provocative connections that can be made between women's writing in other, more commonly discussed genres, and their plays, fundamental differences exist between how we need to think about women's writing for the theater and about their other forms of literary production. Women's playtexts must be contextualized sociologically if they are to be understood in any adequate way. Though literary analysis and textual criticism of the various versions of women's plays are possible approaches that, strategically employed, can illuminate the particular circumstances and strategies of a woman writer, scholarship on women playwrights requires a versatile methodology of inquiry that gathers evidence from widely variable sources that include receipt books, glancing journalistic references, caricatures, advertising bills, personal correspondence, second-hand mentions, and the play texts themselves. In effect, however normalized the social process of women's literary production in other genres, we do not yet know enough about women's complex social authorship of theater texts to read these plays as literary works. To historicize our interpretations, we must view play texts as complexly linked sources of data. 


\section{Building a Venue for Inquiry Stimulates Collegial Discourse}

The value of a Web-based venue that both allows for shared work and accumulation of resources is especially important for women's theater history. Sociological inquiry depends on studies of patterns of activity and a lone scholar can find developing a project based on sufficiently dense information from multiple sources almost overwhelming. Collaboration through the provision of practical leads, sources, and even, potentially, the sharing information might make certain projects possible that would otherwise be inconceivable within the current pace of professional publication. Also, one should considering the types of reading in which those interested in women playwrights might engage - from scholarly data collection and textual editing to performance experimentation and reading out of interest - the approach taken by a performance-oriented reader might stimulate a historyoriented reader to raise new questions. Such cross-fertilization of inquiry is particularly important for work in theater history and performance where so many elements of social process must be part of any robust inquiry into a text, a writer, or a historical period. Of course, collegial interaction, more immediate publication of creative interpretations than books or articles can offer, and even contentious disagreement can affect how inquiry moves forward. The more the discourse thrives within a shared venue . . well, the more the inquiry thrives.

Our four propositions range from statements about the nature of women's theater writing as historical material to comments about the development of new models of scholarly process. It is our view that the rewriting of theater history needs to be informed by ongoing reflection on historiographic practices in order to make the best possible uses of the data-manipulating power of computers and the social activity of groups of colleagues.

\section{ELEMENTS OF THE SITE}

\section{Works}

There are currently seventeen plays available at the BWP1800 site, with several more in preparation to be mounted at the rate of at least one new play every four months; we constantly solicit and receive proposals for new plays proposals from various scholars. By its fourth anniversary in December 2002, the project should be offering quite a rich collection of plays to scholars and students. The first play coded for our project was Jane Scott's Broad Grins or Whackham and Windham; or, The Wrangling Lawyers, a burletta in two acts, first produced at the theater Sans Pareil, London, on 25 January 1814. Jacky Bratton provided the text and an introduction that makes clear one of the major difficulties one faces when preparing texts of plays from the Romantic period for either print or electronic publication. She writes:

The text given here is only the accidentally-surviving shadow of the theatrical event: it is taken from the copy made for the purposes of obtaining a license for performance from the censor's office under the Lord Chamberlain. As such it does no more than sketchily represent the play as performed. This is of course true of all play texts, but it is especially and acutely the case with works like this, whose life was intimately embedded in the situation of their writing and performance, and whose appearance in manuscript was no more than a 
gesture towards legal requirements. This text was never intended as even a blueprint for the real thing; its purpose was only to reassure the authorities that nothing seditious was intended. What actually happened at the Sans Pareil, with the collaborating cast of performers and the regular, knowing, participatory audience who approved of the play, can only be grasped by regarding the ensuing text as a set of clues, whose life is to be found or recreated on the stage. (para. 2)

Consequently, it was agreed that our text of Whackham and Windham was going to be a full, plain-text file of the play, as well as a lightly edited version, coded in HTML and broken down into acts and scenes for easier access and classroom use. The breaking-down of this play, and others, into sections such as acts and scenes, allows the users either to read the text directly from the screen, or to print it out with equal ease. Although we think it is likely that, over time, more and more people will read texts directly from their screens, we are aware of the current problems associated with reading online. ${ }^{4}$ At this moment in online cultural history, however, readers often read texts delivered on the Web by using printouts because they are more comfortable with them. It serves our purposes to format our texts so that they will meet users half way, and so we have begun mounting PDF files of the plays along with HTML texts. Many find these files easier to use in classrooms and rehearsal halls because they contain some of the most useful features of printed plays, such as standardized page numbers for ready reference.

Our principal aim at the BWP1800 project is to make plays available for teaching and discussion, in some cases for the first time since their original performances (as is true for Whackham and Windham) or since their initial publication after their author's death, never having been performed (as in the case of Elizabeth Inchbald's The Massacre). When we began this project, we immediately agreed that we would need lots of input from various scholars on how to make the site useful and how to continue developing its potential. The lack of printed texts of plays written by women playwrights provided us with immediate motivation for adding a series of electronic play texts, but the lack of funding for editorial development prevented us from simply offering dozen of plays within the first two years of our Web site's existence. Consequently, we had to approach this potentially serious limitation creatively, and we have been lucky so far in drawing on the generosity and support of many colleagues who have offered electronic texts for the BWP1800 project. As indicated, Jacky Bratton kindly gave us her transcription of Scott's play, and many other colleagues have followed suit by providing electronic texts, including Jessica Richard (Frances Burney's Love and Fashion), Elizabeth Fay (Hannah Cowley's The Runaway), Diego Saglia (Sophia Lee's Queen of Almeyda), and John Francescina (Elizabeth Polack's Esther, The Royal Jewess and Catherine Gore's King O'Neil). The result has been that we have made a collaborative virtue of our dire need for content.

\section{Essays}

This second major section of the BWP1800 site aims to foster a spirit of discussion and generate scholarly exchange. When we first talked about creating the BWP1800 site in early 1998, we wanted to advance the genuine spirit of inquiry-based community that began in Evanston, Illinois, at a small conference held by Tracy Davis and Ellen Donkin in support of their edited volume Women and Playwriting in Nineteenth-Century Britain, a discussion that had been furthered at the two MLA sessions on British women playwrights around 1800 in 
Toronto and San Francisco. ${ }^{5}$ The positive response to these sessions and the project as it stood in November 1998 encouraged us to create an "Essays" section in the BWP1800 site. Therefore, we started inviting scholars to present their work online, accompanied by a response written by another scholar in order to model and stimulate discussion.

Several scholars have contributed essays or introductions on plays mounted at the site: for example, Jeffrey Cox offered his headnote and notes on Starke's The Sword of Peace (taken from his Pickering and Chatto edition) and Jeanne Moskal wrote a critical introduction to the play, Angela Wright provided an introduction to Lee's Queen Almeyda, and Danny O'Quinn submitted an introductory essay on Inchbald's The Massacre. In another important essay for the site, Lauren Mayer and Julia Flanders of the Brown Women Writers' Project discuss the difference between making a text available in "simple," straightforward HTML coding and offering a full-blown SGML encoding. Mayer and Flanders also consider the complexity of encoding plays as opposed to poems, non-fiction prose, and novels. Kathryn Sutherland responds to their essay by questioning further the problematics of electronic editing and the importance of the role of the editor in shaping a text's form and meaning through encoding decisions.

Recent updates to the "Essays" section include the full text of Syndy Conger's Studies in Philology article “Reading Lovers' Vows: Jane Austen's Reflections on English Sense and Sensibility" (to complement our electronic edition of Inchbald's Lovers' Vows), Barbara Darby's piece "Harriet Lee (1757-1851) and The Mysterious Marriage, or the Heirship of Roselva" (to introduce our electronic edition of this play), and Daniel O'Quinn's essay “The Long Minuet as Danced at Coromandel: Character and the Colonial Translation of Class Anxiety in Mariana Starke's The Sword of Peace" (with a response by Marjean Purinton). The "Essays" section currently contains twenty-five pieces, dealing with issues ranging from the difficulties of teaching theatrical texts and the usefulness of the electronic medium to the important political issues that influenced a play's lack of publication in its author's lifetime.

We are learning through our work on the site that the Web permits new ways of providing peer review and sustained discussion over those that have been the model in print publication. While the quality and significance of issues discussed in the site's essays is not substantially different from print publication, the intimacy of intellectual exchange and continuity of intellectual threads enables a kind of discursive community often difficult to sustain when specialist colleagues seldom work together closely for sustained periods of time. Many involved in the working group met in London, Ontario, at a first biannual conference in August 2002; the meeting featured collegial responses to four draft plenary papers published in advance on the Web site (by Danny O'Quinn, Jane Moody, Gillian Russell, and Jacky Bratton), and included discussion of the plenary papers and responses, workshops, and two additional panels jointly organized with NASSR. A collection featuring essays by conference participants is planned for 2003-4, and another conference scheduled to coincide with NASSR 2004 in Colorado.

\section{Bibliography}

This section provides a listing of articles, books, and collections of essays dealing with women playwrights and Romantic drama, as well as works dealing with humanities computing and electronic editing. New items are frequently being added to the 
bibliography, reflecting the growing interest in this field and the expansion of the $B W P 1800$ project. We hope that academics and students will find references to works as yet unknown to them, and that they will also tell us of missing references that should be included. Over time, we plan to provide annotations for the many entries in the "Bibliography" section. An online bibliography presents some obvious advantages over a printed one, including ease of use and regular updates, as well as hypertext links to other electronic resources and online scholarly projects such as Romantic Circles, Alan Liu and Laura Mandell's Romantic Chronology, and Romanticism On the Net.

Among the various updates planned for the coming year are a new section featuring visual images related to theater and another section offering relevant chronologies. The former will ultimately include video clips of live performances and scanned images, plus discussions of the impact of visual elements on interpreting and teaching plays. The latter will contain several chronologies related to women playwrights, including annotated chronologies of individual authors and general chronologies of dates and events on the period as a whole (such as that taken from David D. Mann and Susan Garland Mann's Women Playwrights in England, Ireland, and Scotland 1660-1823, already available in the $B W P 1800$ project).

\section{EXPERIMENTING WITH SCHOLARSHIP ON THE WEB: TWO CASE STUDIES}

As our project has an experimental approach to the application of the Web's advantages and many possibilities to the investigation of the history of women's dramatic writing in Britain around 1800 , we continue to look for new ways of using our site to facilitate scholarship on particular topics and to explore more of the ways of working on developing knowledge that the Web enables. We are currently developing two contrasting projects for our site that use different aspects of the Web to stimulate scholarly work and insight into how that work takes place.

\section{Joanna Baillie's De Monfort: An Archive}

Why Baillie's De Monfort?

Joanna Baillie was a very successful playwright during her lifetime, certainly in terms of her cultural importance and the reputation of her collection of plays if not for their success on the stage. To mention but two contemporary accounts, Sir Walter Scott, one of Baillie's friends, declared that she was "certainly the best dramatic writer whom Britain has produced since the days of Shakespeare and Massinger" (vol. II, 29). And Lord Byron praised her in several letters to friends, where he alleged that no woman could really write drama but Baillie. ${ }^{6}$

Modern criticism also is largely filled with praise for Baillie, and she is in fact often the only woman playwright mentioned, or included, in discussions of Romantic drama. ${ }^{7}$ Although she was obviously far from being the only woman playwright of her time, nor, it could be argued, the most important one, it is fair to say that the last ten years have seen an increasing number of articles and books dealing with her plays and her theory of drama, most famously expressed in the "Introductory Discourse" to her 1798 volume entitled $A$ 
Series of Plays, in which it is attempted to delineate the stronger passions of the mind, each passion being the subject of a tragedy and a comedy. There is also a collection of essays devoted to her to be published next year by Routledge, as well as new editions of her plays from Pickering \& Chatto and Broadview Press on their way to your favorite bookstores. Therefore, it is not really surprising to find scholars such as Adrienne Scullion declaring that Joanna Baillie is "The most important playwright in nineteenth-century Scotland" and that she was "universally celebrated as the playwright of her generation" (Female Playwrights 160).

Although the BWP1800 project has been attempting to extend the present consideration of women playwrights of the turn of the nineteenth century by introducing many playwrights unfamiliar to modern readers, principally because of the unavailability of their plays, we felt that Baillie would be the best subject of a hypermedia archive because of her current, nearly canonical status. By offering such an archive and therefore attracting a larger audience, we also hope to introduce many other authors and plays to our readers. Since Baillie's De Monfort finds itself regularly assigned in Romantic syllabi, our archive should also be useful to students and teachers alike, with much material that most libraries do not have. De Monfort also has an interesting publication and performance history, which makes it an ideal case study for discussing issues such as reading versus performance, and the editorial choices involved: for example, which text do we choose to include as our main text for the archive? The original version of the play from the 1798 volume? The Larpent manuscript? Or one of the revised versions of the play that Baillie published later on in her life? Finally, as perhaps the most commonly discussed literary play by a woman writer of the period, De Monfort is ripe for the complication of its meaning and historical contexts that hypertext enables.

Another reason for our choosing De Monfort is the play's association with three of the main actors of the Romantic period-John Philip Kemble, Sarah Siddons, and Edmund Kean. This in itself makes it a fitting play for an archive since the materials about these actors that we will include in the De Monfort hypermedia archive will also be useful for other plays in the BWP1800 collection. Indeed, Siddons and Kemble were involved, directly or indirectly, in the production and performance of many other plays written by women playwrights. More specifically, as Jeffrey Cox notes in his edition Seven Gothic Dramas, De Monfort “can be read as an investigation of 'Siddons-mania,' the nearly hysterical response to the performances of Sarah Siddons" (53). Siddons, who played Jane De Monfort in the eight performances that took place at Drury Lane between April 29 and May 9, 1800, has been described by The Oxford Companion to the Theater as "the greatest tragic actress of the English stage" (886). Her brother, John Philip Kemble, not only was the most famous actor since Garrick, but also became the manager of Drury Lane and was involved in the "Old Price" riots in 1809. As for Kean, William Hazlitt wrote numerous times about the unique qualities that this actor possessed and his remarkable range. Although neither the 1800 performances featuring Siddons and Kemble, nor Kean's revival of the play in 1821, were unqualified successes, De Monfort was performed several times in England and in America between 1800 and 1826. Many reviews discussing the play, the actors, and Baillie's writings also can be included in the archive, providing a rich set of contexts for re-reading this most widely read of women's plays of the era.

De Monfort is also an important play in that it provides a twist to the otherwise simple contrast between "closet drama" and "stage drama" in early nineteenth-century studies and 
it raises questions about the effects of gender on authorship. Baillie, rather than claiming to want her plays to be read but not performed as Byron (perhaps disingenuously) did, endeavored to have them both published and performed. Baillie's willingness to reach the public through a mixture of media suggests that disparaging the era's theaters - a strategy that may have been rhetorically effective for male writers with public visibility on their side-was a stance that a woman writer such as Baillie could ill afford when dealing with the men who chose what was produced on stage and published.

\section{How Does One Edit De Monfort as a Hypermedia Archive?}

In editing a play electronically, the relationship between one textual version and another can be significantly more complicated than in the case of a novel or a poem. As opposed to Coleridge's Christabel or Shelley's The Last Man, a play such as Baillie's De Monfort challenges its editor to consider a variety of relationships not only between reader and text, but also between text and text (that is to say the multiple versions with different purposes from the first written to the last revised one), and between text and performance. As Lauryn Mayer and Julia Flanders remark in their essay for the site, when discussing a dramatic text, one should wonder "did text or performance come first? What different kinds of claims to relative authority do the text and the performance have? What effect does this have on our reading of each?" (para 7). This is particularly relevant to De Monfort, with the shift that took place from written text to performed play. Revisions were made to the 1798 version when the play was performed by Siddons and Kemble. Then Baillie revised the text again when Kean revived the play in 1821, and made several more significant changes in subsequent printings of the play later in her career. The changes to the text of Baillie's play, whether in the written versions or in the versions used for performances, indicate a textual fluidity that is characteristic of many plays written during the period. It also makes for difficult editorial choices.

Our archive of De Monfort will be constructed like Jerome McGann's Rossetti archive, "so that its contents and its webwork of relations (both internal and external) can be indefinitely expanded and developed" (para 62). We have in mind a "central text hypermedia" - an electronic edition of Baillie's play, with appended notes and hypertext links, rather than a historical-critical edition, which compares only various versions of the play. The hypertext environment of the Internet allows for the inclusion of other texts by Baillie, primarily prefaces from the various editions of her plays, and in particular the famous "Introductory Discourse" in which she first discusses her dramatic theory. We will include the full text of the three reviews of the 1800 performances that appeared in the Dramatic Censor, European Magazine, and the Monthly Magazine. We will also mount several reviews of the Kean performances in 1821, including the one published in The Examiner, a newspaper with a strong history of theatrical criticism during the Romantic period, especially during the time when Hazlitt wrote for it. There will also be biographical and critical sections on the actors involved in the two Drury Lane productions. Various people will contribute to these sections in the general spirit of collaboration that the BWP1800 project has sustained since its infancy. For instance, Judith B. Slagle, editor of Joanna Baillie's letters, will provide several letters related to the play and its performances, and Daniel E. White will offer some advice on teaching De Monfort in a Romantic studies class. De Monfort's wide cultural circulation 
invites a multiplicity of links to external elements beyond the text, such as additional information about the actors, Drury Lane, and also extracts from the letters and journals of Baillie's contemporaries about her and De Monfort. All these elements can be offered in an electronic archive in a way that no printed edition of the play could ever achieve without running to several thousand pages.

An electronic environment allows an editor, and therefore also a reader, to move beyond the text of the work under consideration, the one that is theoretically at the centre of the archive, but is in fact only one of many important elements. One of the important questions that any editor of a hypertext edition asks him or herself is what are the other principal elements? Editorial notes and significant variants are certainly important elements, as are critical sections on the author and the period. The temptation is often to include many texts that have potential relevance for the most likely users of the archive. To take one example from the play under consideration, one can argue, as Joseph Donohue has, that the character of De Monfort is also the prefiguration of Byron's antisocial and melancholy protagonist in Manfred (81). Should the full text of Manfred therefore be included in the archive? Such decisions about inclusion and exclusion of material are significant because they structure user navigation and "reading" within the archive. These choices govern the users' attention. Ilana Snyder registers this when she remarks, "Hypertext enables text to be organized in new ways, driven by the reader's choice. Because the reader now participates in the structuring of the text, the act of reading becomes correspondingly more conscious" (69). For our project, the ways in which we select and juxtapose materials in the archive enables visitors to "find" connections as they use the archive. For example, Catherine Burroughs' observation in Closet Stages: Joanna Baillie and the Theater Theory of British Romantic Women Writers about the moral interpretation of female costume and makeup in De Monfort (122-125) points the way toward another potential section of the archive-images contemporary to De Monfort depicting women's fashion. In this way, a critical insight informs choices about the content of the archive, and chosen material enables users to explore such a suggestive connection on their own. Once constructed as part of the De Monfort archive, such a section on female costume and makeup will likely influence users' experience of other editions in the BWP1800 project to which the same images will also be linked.

While an electronic archive can include many versions of any given text-extremely useful in representing Coleridge's revisions of a poem throughout his lifetime-a variorum hypertext would still principally be based on extant written records of a text. De Monfort as theater text can never be fully recovered because of the ephemeral nature of theatrical process and public performance. No present day editor can have definitive access to the version performed at the time. That we have manuscript alterations and contemporary reviews for some performances, which indicate some of the changes that the text underwent, is very useful, but it will never fully represent Baillie's play as staged. The closest we can come is to create a hypertext version which allows the reader access to various elements that provoke acts of historical interpretation of the many facets of the performed play. For this reason, the De Monfort archive aims to explore ways that hypertext can function powerfully in theater and drama studies - as a medium less bound by print cultural forms and rhetoric and more conducive to the kind of associative, playful historiography that serves theatrical subjects best. 


\section{What Do We Hope to Learn by Creating This Kind of Archive?}

The emphasis in the Baillie De Monfort archive is on creating a compelling experience of multiple cultural sources for users. In a sense, we use our focus on the material represented to take a somewhat non-directive stance toward the construction of critical discourse. There is an organizing editorial intelligence behind even the open possibilities for interpreting an archive's materials, but we, to a certain degree, avoid specifying too explicitly the particular meanings users might make of what we provide. Our example of the Baillie De Monfort archive that is under development makes use of some of the features of the Web that are widely acknowledged, if not always embraced. By juxtaposing information in multiple media within the structures provided by a familiar user interface (a Web browser), we can invite users to improvise their own links between performance scenes, visual images, period critical commentary, and a dramatic text. If artfully constructed, such an archive can also draw users into discovering provocative ways of interpreting these various "texts" together.

\section{Felicia Hemans' The Vespers of Palermo: A Virtual Collection/Conference}

\section{Why Hemans' The Vespers of Palermo?}

Hemans' is now acknowledged to be one of the key writers of the expanded Romantic canon. In addition, The Vespers of Palermo was staged in Edinburgh through Walter Scott and Joanna Baillie's influence, and this brush with the stage mediated by two other key literary figures of the era provides a rationale for cultivating an exchange of ideas about one of the poet's less-well-known texts. The play itself explores the passions and social dynamics surrounding political rebellion, and therefore has relevance to discussions of other second generation Romantic drama on similar themes (Byron's history plays and P. B. Shelley's dramas, for example). In addition, Hemans' juxtaposition of the experiences of men and women in times of political turmoil invites comparison to Inchbald's unpublished and unperformed The Massacre (already online at the BWP1800 site with an essay by Danny O'Quinn) and to several of Joanna Baillie's plays. Hemans' play can easily be situated within key threads of critical discourse on the Romantic period.

The timing is also right to invite a group of scholars to engage with Hemans' play. While much scholarship on Hemans' poetry continues to be produced, the publication of Susan Wolfson and Elizabeth Fay's parallel text edition of The Siege of Valencia provides an excellent opportunity to invite scholars to take a closer look at Hemans' Vespers in light of that edition's suggestive comparison between a published and manuscript play script. Wolfson's valuable edition of Hemans' writing and her article from the August 2000 issue of Romanticism on the Net on editing the Hemans volume offer further reference points for scholars who participate in our virtual scholarly conference. So, too, do Paula Feldman's 1999 edition of Records of Woman with Other Poems and Nanora Sweet and Julie Melnyk's 2001 collection of essays, Felicia Hemans: Reimagining Poetry in the Nineteenth Century. As we confirmed through inquiries to a few senior scholars actively working on Hemans, existing projects - or interests in developing projects - related to Vespers have been evidenced in conference presentations, personal correspondence, and occasional remarks embedded in publications on other subjects. Timing is essential when organizing a critical moment of opportunity so that scholars, though pursuing different strands of inquiry, can work 
simultaneously on a text that might otherwise only receive scattered attention over a number of years. The timing seems just right to facilitate some exploratory work together on Hemans' The Vespers of Palermo.

\section{What Model of Scholarly Exchange Do We Use?}

The basic structure we envision would involve mounting a text of the 1823 John Murray edition of Hemans' play online. By contacting a number of scholars interested in developing short papers on distinct approaches to interpreting the play, we will coordinate a virtual conference centering on a series of working papers posted to the BWP1800 site by an agreed upon date. Each presenter of a paper would also agree to serve as a respondent for at least one other paper, and the entire submission of papers and responses would be overseen by a senior Hemans scholar. Additional scholars engaged in work on Hemans might also be invited to participate, perhaps contributing short papers on themes that emerge from the group of featured papers.

Based on what we have learned through informal inquiries about scholarly interests or work in progress on Vespers, the featured papers for the virtual conference might explore Hemans' writing on Italian politics and history, her writing on political rebellion, her Eurocosmopolitanism, her career and the place of playwriting in it, her exploration of women's heroism, and the reception of the Edinburgh Vespers production. All contributors/presenters would agree to submit their work on the project's timeline, and develop responses to the work of others after a specified period. Potentially, the online publication of all papers, responses, and perhaps some overview commentary by the senior facilitating scholar could be posted in advance of an in-person panel or two at a planned real-world conference. Should such a gathering take place, participants in the virtual conference could explore further some of the key issues that had emerged from their posted papers since all would have had the opportunity to read these pieces and the responses to them in advance.

While some kinds of shared-topic clusters have been tried in existing online publications, a key variation in this proposed project is the emphasis placed on facilitating not just scholarly production but also social process. With little examined theater texts, opening the door to new ways of working that bring expertise together are particularly important. At the recent mini-conference "Drama and Theater History, 1770-1840: New Approaches, Contexts, and Pedagogies," held in conjunction with NASSR 2002 in London, Ontario, participants found that a similar "working group conference" approach enabled rich exchanges that contributed substantially to the projects featured for discussion. The Hemans project would aim to begin such a working group process by using the occasion of online sharing of work and follow up response.

By developing a network of collegial interchanges, this virtual collection/conference aims to arrive at high quality scholarly discourse through alternative but, we believe, valid means. It provides numerous opportunities for scholarly work to be vetted by peers in ways that actually provide substantive formative review that can influence the direction of the research. In addition, a common space for posting and responding to work invites crossfertilization among distinct projects, creating a timely connection among people working on a text that might seldom receive many scholars' focus at once. Finally, coordinators of the project gain an unusual opportunity to learn about how participation in the project actually affected the development of new knowledge about the subject explored or about the media used to explore it. 


\section{What Results from This Kind of Project?}

It is possible that the draft essays featured in this project could become completed contributions to a journal special issue or other publication. The BWP1800 site itself would take the opportunity to publish the final versions if no other venue did. Regardless of the scholarly products that resulted, we feel confident that a significant result of the project would be enriched thinking about Hemans' writing, particularly The Vespers of Palermo, for all who participate. Participants would also have the opportunity to learn about how professional social and intellectual processes influence each other and how new media can be used to advance inquiry and knowledge development. New insight into the processes explored will be able to inform both classroom and professional scholarly practices, and we would expect that the Hemans' Vespers of Palermo collection/conference would give us good ideas about how to design future experiments in collaborative virtual scholarship.

\section{What Do We Hope to Learn by Creating This Kind of Virtual Collection/Conference?}

It sometimes seems that as scholars we are hemmed in by two anxieties that compound each other when we begin to form interesting interpretive approaches to the works of women playwrights. On one hand, we can feel, though we might be reluctant to admit it, that sharing our good leads and insights before they are written into finished articles will allow someone else to produce a piece of work that we hope someday to publish ourselves. Nothing about this, of course, is unique to research on women playwrights, unless of course you count the proportionally greater cost to the accumulation of knowledge in this emerging field of even a handful of long-delayed or unfinished pieces of good scholarship. However, at the same time, we can sometimes find that other projects-perhaps on the poetry or other writing of a woman whose drama interests us, or on dramatic writing with an already established critical history-seem more professionally strategic because they engage other scholarship in ways our profession values. A result of this double anxiety is that good ideas for scholarship on plays like Hemans' The Vespers of Palermo never quite make it to print and so discussion of such a play, which might otherwise take place and make a significant contribution to studies of Hemans, Romantic drama, and women's writing generally, remains undeveloped-merely the stuff of spontaneous exchanges at conferences, in email, or in short digressions in critical work on other subjects.

While print published scholarship remains the standard by which scholars' work is measured, we need to question whether in every case the work processes that print encourages always serve dramatic works and theater histories that have not yet been given their due in scholarly discussion. By providing an occasion for shared interests in a text like Hemans' Vespers to serve as the basis for a temporary scholarly community of practice, we hope to support work on this intriguing play and playwright, but also to stimulate thought about the limits of existing scholarly practices and media and the potentials of new ones.

\section{CONCLUSION}

We began our work on this project suspecting that the media and practices of professional scholarship might be inherently resistant to dealing with the history of women playwrights, particularly those from the British Romantic period. We remain firmly convinced that 
there are deep paradigm discontinuities between the material culture of humanities scholarship and the histories of women playwright's social/literary activity in the years around 1800. Lack of attention to these women playwrights was not merely a choice at the level of content - that is, a preference against plays or against the writing of women ... though both of those are surely part of the neglect - but a deeply structured resistance to the kinds of practices that inquiry into this material might provoke. Professional scholarship is founded on publication of criticism, rigorously vetted scholarly editions, quarterly journals, annual conferences; it has not typically supported frequent experimental performances, collaborative residencies of peers, ongoing discussion spaces, or informal reading and performance inquiry groups. Scholars of women's theater history must often sustain themselves as more-or-less isolated specialists, not as members of collaborative communities of interest; that is, they are members of academic departments, not of feminist theater ensembles. We suspect that online projects like ours can function in the short term as gestures, interventions - thus, our project has much in common with performance in the ways it can exert pressure on historical discourse. So, in effect, we are experimenting with the creation of an alternative venue for collective historiographic work and continuing to ask what online media have to offer.

The LAB/Education Alliance at Brown University and University of Montreal

\section{NOTES}

1 The British Women Playwrights around 1800 project can be found at the following URL address: http://wwwsul.stanford.edu/mirrors/romnet/wp1800/. From there, you can access all the essays and plays mentioned in this essays, as well as the bibliography section.

2 For a sample of recent and forthcoming editions of, or including, women playwrights around 1800, see Cox and Gamer, Crochunis and Eberle-Sinatra, Burns and Baines, and Scullion.

${ }^{3}$ Such a possibility is not merely a scholar's fantasy. A recently funded project, "The First 100 Years of the Professional Female Playwright," was initiated by two theater practitioners, Mallory Cattlet and Gwynn MacDonald. In October 2002, the project begins a year-long series of play readings and scholarly symposia in New York City. To learn more about the events sponsored by this project that focus on the five featured playwrights-Aphra Behn, Susanna Centlivre, Hannah Cowley, Elizabeth Inchbald, and Joanna Baillie-write to the project email address, duchessofnewcastle@yahoo.com.

${ }^{4}$ Judith Pascoe, Bruce Graver, and Thomas C. Crochunis discuss the problems of reading from a computer screen-as well as the potential pitfalls of online projects, the importance of maintaining peer-reviewed, high standards for texts in scholarly projects on the World Wide Web, and the challenges of engaging academics unfamiliar with electronic technology - in their collaborative dialogue/essay, available at the BWP1800 site. In addition, David Miall suggests new ways of reading hypertexts in an article entitled "The Resistance of Reading: Romantic Hypertext and Pedagogy," published in Romanticism On the Net.

5 More information on these MLA sessions is available at the BWP1800 Web site.

${ }^{6}$ See, for instance, Byron's Letters and Journals, vol. IV, p. 290.

7 Susan Bennett examines the peculiar appeal of Baillie among literary historians in her essay "Outing Joanna Baillie."

\section{Works Cited}

Bennett, Susan. “Outing Joanna Baillie.” Women in British Romantic Theater: Drama, Performance, and Society, 1790-1840. Ed. Catherine Burroughs. Cambridge: Cambridge University Press, 2000.

Burroughs, Catherine. Closet Stages : Joanna Baillie and the Theater Theory of British Romantic Women Writers. Philadelphia, PA: U of Pennsylvania P, 1997.

Burns, Edward and Paul Baines, Eds. Five British Romantic Plays, 1776-1821. Oxford: Oxford UP, 2000. 
Bratton, Jacky. "Introduction to Whackham and Windham; or, the Wrangling Lawyers." British Women Playwrights around 1800 (15 October 1998): 3 paras. 16 September 2002. http://www-sul.stanford.edu/mirrors/romnet/ wp1800/essays/whackham_intro.html

Cox, Jeffrey N., Ed. Seven Gothic Dramas, 1789-1825. Athens: Ohio UP, 1992.

- and Michael Gamer, Eds. Romantic Period Drama: An Anthology. Peterborough, Ontario: Broadview Press, forthcoming 2002 .

Crochunis, Thomas C. and Michael Eberle-Sinatra, Eds. The Broadview Anthology of British Women Playwrights, 1777-1843. Peterborough, Ontario: Broadview Press, forthcoming 2003.

Davis, Tracy C. and Ellen Donkin, Eds. Women and Playwriting in Nineteenth-Century Britain. Cambridge: Cambridge University Press, 1999.

Hartnoll, Phyllis, Ed. The Oxford Companion to the Theater. 3rd edn. London: Oxford U P, 1967.

Mann, David, Susan Garland Mann, and Camille Garnier, Eds. Women Playwrights in England, Ireland, and Scotland, 1660-1823. Bloomington, Indiana: Indiana U P, 1996.

Mayer, Lauryn and Julia Flanders. "Real Editions for Real People: Electronic Editing and Women's Theater Writing." British Women Playwrights around 1800 (15 April 1999): 17 paras. 16 September 2002. http://wwwsul.stanford.edu//mirrors/romnet/wp1800/essays/real1.html

McGann, Jerome. “The Rationale of Hypertext”: 79 paras. 16 September 2002. http://jefferson.village.virginia.edu/ public/jjm2f/rationale.html

Marchand, Leslie A., Ed. Byron's Letters and Journals. 12 vols. London: John Murray, 1973-82.

Miall, David S. "The Resistance of Reading: Romantic Hypertext and Pedagogy." Romanticism On the Net 16 (November 1999): 5 sections. 16 September 2002. http://users.ox.ac.uk/ scat0385/reading.html

Pascoe, Judith, Bruce Graver and Thomas C, Crochunis. "Electronic Editing: A Dialogue between Judith Pascoe, Bruce Graver, and Thomas C. Crochunis.” British Women Playwrights around 1800 (15 July 1999): 14 paras. 16 September 2002. http://www-sul.stanford.edu/mirrors/romnet/wp1800/essays/emaildis.html

Mandell, Laura and Alan Liu, Eds. Romantic Chronology. 16 September 2002. http://english.ucsb.edu:591/rchrono/

Scott, Walter. The Letters of Walter Scott. Ed. H. J. C. Grierson. 12 vols. London: Constable, 1932-6.

Scullion, Adrienne, Ed. Female Playwrights of the Nineteenth Century. London: Penguin, 1996.

-. "Some Women of the Nineteenth-Century Scottish Theater: Joanna Baillie, Frances Wright and Helen MacGregor." A History of Scottish Women's Writings. Eds. Douglas Gifford and Dorothy McMillan. Edinburgh: Edinburgh U P, 1997.

Snyder, Ilana. Hypertext: The Electronic Labyrinth. New York: New York U P, 1996. 